\title{
ATATÜRK VE MUSİKİ
}

\author{
Doç. Dr. Ahmet.ÖZGIRAY*
}

İnsanlar dünyaya yaşamak ve mutlu olmak için gelirler. Sıkıntıyı sevmezler, neşeli olmak isterler. Neşe kaynaklarından biri de musikidir.

Notaya alınabilen seslere müzik denir ve sesler ahenklidir. Duygula$\mathrm{n}$, düşünceleri ve hisleri sesle anlatır ve kültürün nesilden nesile geçişini sağlar. İnsanı rahatlattığı için stresin karşı silahıdır. İnsanlar başta müzik olmak üzere bazı diğer kaynaklardan zevk alarak gevşemezler ise, insan beyninin salgıladığı katokalaminler veya katoşiminler vücutta telafisi mümkün olmayan tahribatlara yol açarlar.

Dilimizde müzik veya musiki adı altında sözcük Türkçe'ye Fransızca'dan geçmekle birlikte asıl Yunanca müzikiye dayanmaktadır.

Hangi toplum olursa olsun, yeryüzünde müzik değişik açılardan bazı türlere ayrılmaktadır. Bu ayrımda ya aynı anda çıkartılan ses sayısına ya da insan sesinin kullanılıp kullanılmadığına bakılarak ikiye ayrnlır:

a- Tek sesli (modal): Etkinliğe katılan, bütün kişilerin ve sazlann aynı anda aynı bir sesi çıkartmaları, aynı notayı seslendirmeleri.

b- Çok sesli (polifonik): Aynı anda değişik seslerin çıkartılması ayn notalann seslendirilmesi.

İkinci bir ayrım da müziğin yalnız sazlarla ya da hem saz hem de insan sesleriyle birlikte icra edilmesidir.

Cumhuriyetin ilk yıllannda ülkemizde tek sesli, modal müzik alaturka, çok sesli batı müziği alafranga olarak adlandınlmıştır. Fakat son yıllarda bu ayırım genç kuşaklar tarafından unutulmuş, Anadolu'ya geldikten sonra yerel kültürler de Türk müziğini etkilemeye başlamıştır.

Kökeni Orta Asya olan ve Türk halkı tarafından yaratılmış olan kültür ögesi Türk göçleri ile birlikte, bir yandan Karadeniz kuzeyinden Ma-

* Ege Univ. Ed. Fak. Tarih Bölümü, Oğretim Uyesi. 
caristan ortalarına, öte yandan Anadolu yolu ile Rumeli ye kadar yayıld1ğ görülmektedir'.

10. yüzyılda Türklerin İslamiyeti kabul etmesinden sonra, milli degerlerini koruyamadıklanndan müzik kısmen de olsa Arap ve İran'ın özünü günümüze kadar koruyabilmiştir. Arap ve İran müziği etkisi altında kalan Türk müziği gam ve hüzün neşreder. Temelde sermayesi kadın ve rakıdır. Bugünün sanat, klasik ve tasavvuf müziği gibi türlere aynlmak istenen tek sesli modal müziğin kökeni henüz kesinlikle saptanmamakla birlikte, 13. yüzyılda biçimlendiği kabul edilmektedir.

Selçuklulardan başlayarak Osmanlılar döneminde Türklerin icra ettikleri müziğe de Türk usulü anlamına gelen alla turca (alaturka) denilmiştir. Frenk usulü, Avrupa usulü demek olan alla franca (alafranga)'nın karşılığında kullanılan alla turca, yalnız müzik için değil, Türklere özgü nitelikler, kültürel ayrımların tümü için geçerli bir deyim olmuştur ${ }^{2}$.

Batılılaşma girişimlerinde alaturka deyimi yabancılar tarafından değil, doğrudan doğruya Türk aydınlanınca küçültüicü, aşağılayıcı anlamında kullanılır olmuştur.

Öte yandan, halk müziği, yüzyıllar boyunca varlığını ve etkinliğini sürdürmektedir. Toplumun akışına göre renklenir ve zenginleşirken icrada ve kullanılan araçlarda zamanlarda bazı değişikliklere uğramıştır. $\mathrm{Bu}$ arada ozanların kullandıkları kopuzun yerini Farsça her türlü müzik aletine verilen ad olan saz olmuştur. Bu da halk müziğinde bağlama ve cura gibi telli çalgıların tümü için kullanılmaktadır ${ }^{3}$.

19. yüzyıla gelinceye kadar, Avrupalıların çok sesli müziği Türk toplumunca hiç bilinmez değildi. İmparatorluk içindeki Müslüman olmayan tebaa ile İstanbul'da ve bazı büyük şehirlerde yaşayan Levantenler bir bakıma çok sesli müziğin temsilcileri idiler.

II. Mahmud'un 1826'da Yeniçeri Ocağı'nı kaldırırken Mehterhane'yi de kapatması ordu müziğinde bir boşluk yaratmıştır. Asakir-i Mansure-i Muhammedi'yye adı verilen yeni bir ordu oluștururken batı ordulannda olduğu gibi, bir askeri bando kurulması uygun görülmüştür. Bu amaçla batılı bir uzman aranması çok sesli müziğe de kapılanı aranmasını sağlamiştur.

1. Ibrahim Kafesoğlu, Türk Milli Kültürü, Istanbul 1986, s.69.

2. Serafettin Turan, Türk Kültür Tarihi, Istanbul 1990, s.259.

3. Y̌lmaz Öztuna, Türk Musikisi Ansiklopedisi, Istanbul 1974, C.2, s.42-43. 
Serasker Hüsrev Paşa, 1827 Temmuz'unda Sardunya temsilcisinden kurulması düşünülen ordu bandosuna benzer bir müzik topluluğunda görev alacak olanları yetiştirmek için bir şef gönderilmesini istemiştir. Yazışmalardan sonra buna ilişkin bir sözleşme metni de hazırlanmıştır.

Gelecek olan şef, bayramlar ve cuma tatilleri dışında her gün 6 saat ders verecekti. Doğrudan doğruya bir saray yetkilisine bağlı olacak ve kendisine yılda 8000 Fransız Frangı ödenécekti. Ayrica bir lojman verilecek, yiyecek ve içeceği sağlanacaktı ${ }^{4}$.

Böyle bir sözleşme yapıldıktan sonra Sardunya yetkililerinin seçtiği Giuseppe Donizetti, mensup olduğu alaydan üç yıl için izin almış ve 13 Aralık 1827 'de İstanbul'a gelmişti ${ }^{\text {. }}$.

Muzıka-yı Hümayun adı verilen yeni bando takımını kurarak göreve başlayan Donizetti, 1831'de Üsküdar'da açılan Muzıka Mektebinin yönetimini de üstlenmişti. Burada örgün bir müzik eğitim-ögretimi de yapıldıgından bu kuruluş, bir bakıma bir konservatuvar demekti.

Donizetti, göreve başlamasından bir yıl sonra padişah için Mahmudiye marşı bestelemişti. II. Mahmud kendisi de Türk musıki alanında birbirinden güzel bestelere sahip bir bestekardı.

Günümüzde Cumhurbaşkanlığı Senfoni Orkestrası olarak etkinliğini sürdüren Muzıka-yı Hümayun'un kurucusu Donizetti, aynı zamanda Türkiye'ye çok sesli müziğin kişi olarak da girişinde önem taşımaktadır.

Padişahın takdirlerini kazanan Donizetti Osmanlı ordusunda 28 yıl çalışmış ve mirlivalığa (tuğgeneralliğe) kadar yükseltilmiştir. Osmanlı subayı kıyafetine bürünen ve bir Türk gibi yaşayan Donizetti Paşa 1856'da İstanbul'da ölmüştür.

Atının eğerini dahi Avrupa'dan getirten II. Mahmud, her payı Avrupalı yapmak istemiştir. Bu sebeple Türk müziğinin yanısıra çok sesli müziğe de yer vermiştir.

Aynı gayreti bir asır sonra 29 Ekim 1923'de kurulan Cumhuriyet idaresi göstermiş ve kendisini modernleştirmek ve Avrupa tipi yeni müesseseler yaratarak Osmanlı İmparatorluğu mirasından uzaklaşmak için büyük bir enerji ve para harcamaya başlamıştır. Zira Osmanlı kurumlan 20. yüzyılın ilk yarısında çökmüştü. Tekrar diriltmek mümkün değildi.

4. Şerafettin Turan, a.g.e., s.268.

5. Tuncer Baykara, Osmanlllarda Medeniyet Kavramı 19. Yüzylla Dair Araştırmalar, Izmir 1992, s.66. 
Diriltilse dahi onlara işlerlik kazandırılamazdi. Halbuki başka ülkelerde asırların bıraktığı kültür birikimi gurur duyulan miras olarak nitelendirilmesine karşın, Türkiye'deki yeni rejim kiyıda köşede eskiden kalma ne kadar tozlu kültür parçası varsa, süpürmek zorunda kalmıştır. Türk hükümetinin modern ve milli kültür oluşumu yaratmak için takip ettiği bu yolun bir başka ömeğine, bir başka ülkede rastlamak mümkün değildi. Fakat başka bir altematif yoktur, çünkü Osmanlı kurumlan zayıf olduğu için çökmüştü.

O günün Türkiye'si yapabileceğinin en azını yapan, alabileceğinin en azı ile yetinen bir ülke durumundaydı. Nihayet duygulan körelen, ahlak ölçüleri gerileyen, dürüstlük kavramı zayıflayan, insanlan birbirlerini daha az seven, iç güzelliğini yitiren bir topluma dönüşmüştür. Çağdaş bir toplum yaratmak için Türk milletine yeni yolunda öncülük yapan liderin müziğe karşı gösterdiği ilgi bir çok yenileşmelerden birisidir ${ }^{6}$. Buradan tıpkı diğer reformlarda olduğu gibi, ilham rüzgarları yukarıdan aşağıya estirilmiş, zamana ve şansa bırakılmamıştır. Kendi öncülüğünde ve himayesinde Cumhurbaşkanlığı Senfoni Orkestrası adıyla bilinen orkestranın kurulmasında öncülük eden Gazi, bunu daha evvel faaliyete geçirmek istemiştir. Kadrosuzluk ve yetişmiş kişilerin eksikliği nedeniyle faaliyete geçirilememiştir. Nihayet 1926 'da orkestra şefliğine getirilen Osman Zeki Bey, milliyetçi müzisyen olup, Gençliğinde Berlin'de müzik tahsili yapmış, sonradan Türk Ordusunda müzik direktörü olarak görev almıştır?.

Müzisyenlerin tamamının Türklerden oluşan orkestra, Osman Zeki Bey'in enerjik ve disiplinli çalışma önderliğinde orkestra yüksek teknik standartlara ulaştı. Illk yıllarda yetenekli bir orkestra tarafından icra edilen klasik bestecilerin eserlerini kulaklan rahatsı edici bir şekilde çalmışlardır. Lakin gayretli ve sabırlı çalışmanın ürünü olarak uyumlu bir müzik topluluğu ortaya çıkmıştır.

1930'dan sonra bu orkestra, kı̧̧ dönemi boyunca Ankara'da haftalık ücretsiz konserler vermiş, bütün halka açık tutulmuştur. Konser salonunun müzikten anlayan kişilerce doldurulması gelecek yıllar için sağlıklı

6. Mustafa Kemal Paşa'nın 19. Fırkası Canakkale'de Carmen operasından parçalar çalıyordu. H.C. Yalçın baskıya hazırlayan R. Mutluay, Siyasi Anılar, Ist. 1976, s.225.

7. Osman Zeki (Ungör): 1880 'de Úsküdar'da doğdu. 11 yaşında saray Muzıkasına yazdirild. Italyan Pepini Gayto'dan, Fransiz Vandro'dan keman dersleri ve Saffet Bey'le B. Arondo Paşa'dan, musiki nazariyatı dersleri almıs; konserlerde mükemmel bir virtiyöz olarak tanınmıştır. Sonra saray Orkestra şefi oldu. Istanbul erkek Muallim Mektebi'nde uzun zaman musiki öğretmenliği yaptı. Birinci Dünya harbinde orkestra ile bir çok Avrupa şehirlerini dolaştı. Sonra Ankara'ya gitti. Musiki Muallim Mektebini kurarak müdürlügüune geçmişti. 1934'de kolunun ağrumasından dolayı emekliliğini istedi. Istiklâl Marşını beslemesi yanısıra başka muvaffakíyetli besteler yapmış ve bir hayli talebe yetiştirmiştir. bkz. Ibrahim Alaaddin Gövza, Türk Meşhurları Ansiklopedisi, s.393. 
işaret veriyordu. Programlar tanınmış bestekarların klasik eserlerinden 1930'lu y1llara kadar olan eserlerini ihtiva ediyordu. Elde mevcut imkan ve kaynaklar ölçüsünde dinleyiciye iyi müzik aşllama arzusuna dayanan bir düzenlemenin gayreti vardı. Orkestra iyi bir ses tekniğine sahip olmakla birlikte, büyük bestekarların eserlerinin tam yorumunu yapmak için gerekli olan ilham ve maharet henüz sahip değildi. Orkestra mevcut zorluklarına rağmen, her yıl daha yüksek standartlara ulaşıyordu. 1931 sezonunun konserler dizisi, biraz geç olarak verilmesine rağmen, canlı ve heyecanlı geçiştir. Nitekim Bethoven'n Choral Symphony'sinin dokuzuncusu 110 kişiden oluşan bir orkestra ve koro eşliğinde icra edilmiştir. Buna benzer konserler, ücretsiz olarak Halk Partisi'nin merkezleri durumundaki Halk Evlerinde verilmiş ve oldukça fazla dinleyici cezbetmiştir ${ }^{8}$.

Ankara'daki Müzik Okulu müzik kültürünün ülkede yayılması açısından Cumhurbaşkanlığı Senfoni Orkestrası'ndan daha önemli bir yere sahiptir. Bu okulun müdürlüğüne Osman Zeki Bey getirildi. Müzik ögretmenlerini yetiştirmek amacıyla kurulmustur. Müzik kabiliyeti olan 14 yas civanndaki kız ve erkek çocukların yatılı olarak alındığı bu okulda; öğrenciler Milli Eğitim Bakanlığı bünyesinde çalıştırılmak üzere öğretim ve eğitim yaptınlıp diploma verilerek Türkiye'nin çeşitli bölgelerine öğretmen olarak gönderilecekti. Bu öğretmen adaylarına 1931 yılında Varşova Konservatuvan mezunlarından M. Kasimir Chekotovski aynt zamanda Varşova Operası görevlisi ve kız kardeşi Marie Chekotovski bu okula şarkı söyleme tekniğini öğretmek amacıyla öğretmen olarak tayin edildiler'.

Esas görevlerine ek olarak da öğrencilerine bale dansı fikrini yerleştirmek 'için de vazife verilmişti ${ }^{10}$.

Türk müziğine yeni bir şekil verme gayreti çok aşırı idi. Kendi sahasında uzman bir kişi olan Osman Zeki Bey, çeşitli motifler içerisinde olan seçkin ve ahenkli bir karışım müzik türünü yaratma formülü üzerinde epeyce mücadele etmiştir. Fakat her ne kadar tekniği Avrupalı gibi gözükmüş ise de, ilham kaynağını orijinal Türk duygusu oluşturuyordu. Nitekim Avrupa müziğinden alıntı sağlanması sorunu, ilham yoluyla ülke müziğine ne vereceğini ifade eden unsurlar ve çizgiler doğrultusunda bazı küçük beste denemeleri gerçekleştirilmiştir. Bu iş ilk başlangıçta kolay değildi. Zira uygulama ve adaptasyon görevi tabii olarak zor ve sabır isti-

8. PRO FO 371-E 529144 Turkey, Annual Report, 1932, G. Clerk'ten John Simon'a Ankara 17 Ocak 1933, s.28.

9. Faruk Yener, Türkiye' de Opera Sanatı. Türkiye Ansiklopedisi, C.9, Istanbul 1983, s.2548-49.

10. PRO FO 371-E 529/44 Turkey Annual Report 1932, G. Clerk'ten John Simon'a, Ankara 17 Ocak 1933, s.29. 
yordu. Bu sıralarda Osman Zeki Bey doğu türündeki müzik şeklini saf dışı bırakmaya çalışıyordu.

Türklerin gelecekteki milli müziği Avrupa camiasının müzik türünde oluşacak ve Avrupalılann kulağına hoş bir şekilde hitab edecekti. Bu amacı gerçekleștirmek için İstanbul sehir meclisi müzik mütchasıslannı ki bunlardan birisi olan besteci ve eski Avusturya Devlet Müzik ve Tiyatro Sanatı Direktörü olan Profesör Dr. Josef Marx'1 davet etti.

1932'den 1934 yılına kadar her sene İstanbul'da birkaç hafta görev yapan J. Marx, müzik çalı̧̧malanının genelinde daha iyi ç̧itimin gerçekleştirilmesi ve konservatuarda reform yapılması için öncrilerde bulunuyordu. İstanbul vali ve belediye başkanı olan Muhiddin Bey (Üstündağ) bu profesörün tavsiye ve ögütlerini enerjik bir şekilde hemen uygulardı. Bilhassa konservatuann ihtiyacı olan profesör ve diğer ögretim üyelerini yerli ve yabancı kişilerle doldurmaya çalışıyordu. Konservatuar için bir orkestra kurulmasını sağladı. Ayrıca Enstitüyü geliştirecck diğer önlemleri de aldı. Böylece vali İstanbul için müzik külttürüne büyük hizmetler verdi. Gelecek için ömekler ipuçlann ve koro için pratik ve üzerinde Profesör Marx da hayli önemli katkılarda bulundu. Josef Marx bunu yaparken Türk halkının özelliklerini ve geleneklerini göz önüne alıyordu.

Konservatuann ıslahı için getirilen Josef Marx, 12.11.1932 günü işe başlamıştır. Marx, Viyana'nın tanınmıs bestekarlarındandır. Aynı zamanda Viyana Konservatuar muallimlerinden olan mütehassıs Viyana Yüksek Musiki Okul Müdürü ve Musiki Akademisi öğretmenidir. Şarkı ve birçok orkestra için besteler yapmıștır. Musikiye ait birkaç eser neşretmiștir. Piyano ve ork çalmakta mahirdi. Tokatlıyan Otelinde oturmakta olan Marx'ı kendini ziyarete gelenlere: "Türk musikisi hakkında çeșitli eserler okudum. İzahları dinledim. İyi güzel bir musiki, garb musikisi Türk musikisi beraber tedris edilmeli, yeni böyle inkışaf eder. Bundan yüz sene evvel Ruslar da aynı yolu izlediler. Türkler teknik itibariyle şarklılığını muhafaza etmelidir." demiştir ".

Fakat yenilik çalışmaları öyle bir düzeye geldi ki, genç Türk müzisyenlerinin aklından geçen fikir, Türk müziğinin terk edilmesi şcklindeydi. Halbuki Avrupalıların kulağına ahenk ve ton olarak yabancı gelen Türk müziği, ahenk ve çok seslilik ile Avrupa müziğinin gelişmesi takip edilseydi, Türk müziği gerçek bir sanat olabilirdi ${ }^{12}$.

11. Bkz., Milliyet Gazetesi, 19.11.1932.

12. August Ritter Von Kral, Atatürk's Land Evulation of Modern Turkey, Almanca'dan Ingilizce'ye tercüme eden Kennth Banton, Leipzig 1938, s.169. 
Bunu gerçekleştirmek için ve bilhassa Türk Halk Musıki tonunu sanat değeri yüksek bir seviyeye ulaştırmak için, musiki kabiliyeti olan 14-15 yaşlanındaki erkekler ülke çapında toplandı. Konservatuar binasına bitişik yurt inşa edilerek buraya yatılı olarak alındılar. Böylece, Enstitüde 300 'ü gündüzlü ve 100 'ü yatılı olmak üzere 400 talebesi vardı. Konservatuar orkestrası da 50 kişiden oluşuyordu. Bunlarnn kimisi okulu bitirmiş, kimisi de çok yetenekli talebelerdi. Bu orkestra kondoktör Cemal Reşit Bey ve Seyfettin Asaf yönetiminde kış sezonu boyunca aylık olarak klasik çağdaş müzik konserleri veriyordu.

Konservatuarın, öğretim kadrosunda, piyano için 4, keman için 4, teori ve şan için 3, violonsel için 1 , nefesli sazlar içinde 6 hoca vardı.

Bunların arasında Nurullah Şevket Taşkıran; şan ve koro, Nimet Vahit; keman ve şan, Cemal Reşit Rey; piyano teori, Ferdi Von Stazer; piyano tarihi ve pratiği, Seyfettin Asaf ve Ali Sezgin; keman, Sezai Asaf; cello, Muhittin Sadık; teori ve koro şanı, Luco Amar, keman ve oda müziği, Cemil Bölener, klarnet, Avusturyalı Ernest Kablinger, Khan ve Eidler, flüt ve obua, basıon ve korno için üstad olarak göze çarpıyordu.

1 Kasım 1934 yılında Cumhurbaşkanı, T.B.M.M.'sinin açılış konuşmasında; Türk müziğinin daha hızlı yenileşme ve reorganizasyon için daha fazla çalışması gerektiği konusunda ilgililere ciddi bir şekilde uyarıda bulundu ${ }^{13}$.

Gazi Paşa bunu yapmakla Avrupa müzik standardını yakalamak ve yapılan inkılab hareketlerini kökleştirmek istiyordu. Bu yolu 1948'de İsrail devletinin kuruluşu denedi ${ }^{14}$.

Gazi uyarısı üzerine, hükümet istenilen amaç doğrultusunda halkın sempatisini kazanmak için çeşitli adımlar attı. Sözgelimi, Avrupa müziğini yorumlayan veya Türk müziğini Avrupa müzik kurallarına kompoze eden Türk müzisyenlerine imtiyazlar tanıdı. Hatta hükümet daha ileri giderek halka daha sık parasız konser verilmesini okullarda musiki eğitim kurslan açılmasını ve dış ülkelerde Türk müziğini tanıtma çabasına girdi.

Halk eski müziğinin söz ve makamlanını bulmak için, yurt çapında taramaya girişti. Bu işi mütehassıslardan kurulu bir kurul zevkle yapıyordu. Konservatuann gramafon ve taş plaklan koleksiyonu da rekor seviyeye erişti.

13. Atatürk' ün Söylev ve Demeçleri, C. 1, Ankara 1961, s. 378.

14. 1948 senesinde Israil'de 6 daimi ve 50 senatör tiyatro grubu vardir. Ayrica 4 orkestra, 1 opera ve 100 koro vardı. Security and Middle East By Twenty Distınguished American, Washington 1950, s. 148. 
Bu komisyonun içerisinde; Yusuf Ziya Demirci, iyi ud ve cello çalan Mesut Cemil, modern halk ve klasik Türk müziği yorumcusu Münir Nureddin Selçuk da yer alıyordu.

Hükümetin yeni kararlan arasında müzik öğretimine daha fazla önem verme, müzik okullan açma, yurt binaları inşa ettirme ve senfoni orkestrası kurma da yer alıyordu.

Ankara'nın başlıca amacı: müzik eğitim kolejini ve orkestrasını yeniden toparlamaktı. 1934 kışında, Osman Zeki'nin konservatuardan aynlışından sonra, onun yerine gelen Graz'lı profesör Herman Von Schmeid'in ve müzik alanında bir eksper olan Berlin Müzik Akademisinde çalışan bestekar Paul Hindemith'i Milli Eğitim Bakanlığı yılda iki defa Türkiye'ye davet ederek onlanın tavsiyeleri doğrultusunda 1935 yılından sonra konservatuar bünyesinde yeni düzenlemeler yapt.

Osman Zeki'nin orkestrasının yerine geçen daimi senfoni orkestrası ilk etapta bir kültür başansı olarak değerlendirmek yerinde olur.

Yukarıda görüldügüü gibi, bu iş Atatürk'ün girişimi ile başladı ve Başvekil İnönü'nün, Milli Eğitim Bakanı Saffet Arnkan'ın gayretleri ile gerçekleşti.

Orkestrada 80 kişi görev yapıyordu. Bunlann içinde çeşitli enstrumanlann başında yabancı mütchassıslar olduğu gibi, çoğunluğu Türkler teşkil ediyordu.

Orkestra belli bir süre öyle bir seviyeye erişti ki, Avrupalılara propaganda yapmak için haftalık olarak modem Türk müziği konserleri veriyordu ${ }^{15}$.

Son çalışmalarını Berlin ve Weimer'de yapan müzik profesörü Ernest Pratorius Ankara'ya müzik işleri direktörü olarak atandi. Bu şahıs müzik okulu ve orkestraya tamamen batılı bir ruhla önderlik yapıyordu. Buna Türk ve Alman öğretmenler yardım ediyorlardı. Tanınmış Hasan Ferit Alnar da ikinci kondoktör olarak vazife yapiyordu.

Ankara'daki Müzik Eğitim Koleji devlet okullan öğretmenlerine zaman zaman seminerler düzenliyordu. Bu müzik kolejine profesör Demeth'in girişimi ile müzik faaliyetleri için yeni bir öğretim binası ilave edildi. Burası Profesör Pratorius'in nezareti altında yönetiliyordu. Ayrica idari menejer olarak Rauf Bey görev yaparken ikinci sanatkar direktörü olarak Necil Kazım (Akses) vazife almıştı. Buradaki öğretimde, Necil Kazım ve Hasan Ferit teorik, Berlinli iki asistan ile profesör Lahmann şan, Ulvi Cemal, Ferhunde piyano derslerinde görev almışlardır.

15. August Ritter, a.g.e., s. 170. 
İstanbul Konservatuarı gibi Ankara'daki Müzik eğitim koleji bir yurt binasına sahipti. Bu değerli gayretlerin sistematik kombinezasyonu nihayet meyvelerini verdi, her ne kadar düşük formda da olsa türk milli müziginin Avrupa tarzında yorumu hızlı bir gelişme gösterdiği ve yeni genç bestecileri Türkçe bir sanat modeli yarattılar. Bunların arasında: Cemal Reşit Rey, Hasan Ferit Alnar, Necil Kazım Akses- Ulvi Cemal, Seyfettin Asaf, Adnan Bey, Nurullah Şevket, Mesut Cemal ve Mustafa Fuat vardı.

Bu sanatkarlann çalışmalan ülke sınırlan dışında da bilinmeye başladı. Başkan ülkeleri Avusturya, Almanya ve Fransa'daki konserlerde ve radyo programlanında bunların çalışmalarına yer veriliyordu. Böylece Türk müziğinin rejenerasyonu ve optimistik zanların müsaade ettiği ölçüde ileriye hizla gidiyordu ${ }^{16}$.

Türkiye'nin bütün müesseseleri çağdas olmak zorundaydı. Musikinin yenileştirilmesi gerekiyordu. Çünkü Osmanlı toplumu 1665 'den sonra devamlı olarak batı toplumu tarafından örselendiği için gam ve kasvet içindeydi. Halbuki insanlar dünyada neşe ve mutluluk içerisinde yaşamak isterler. İslam dini gam ve kasvete karşıdır. Halbuki Türk müziğinin en neşeli parçası bile bir hüzün ifade ediyordu. Halbuki Türk klasik ve halk müziğinin bazı iyi besteleri hariç iki ayağı kötürüm vaziyette idi. Bir ayağı rakıya bir ayağı da kadına dayanmışı, hüzün ifade ediyor ve nameleri kulaklan tırmalayan bir hırnltı şeklindeydi.

Bunu Neyzen Tevfik: "Bit gibi toplanmışlar, it gibi hırlaşıyorlar" şeklinde ifade etmiştir ${ }^{17}$.

\section{Sonuç}

Türkiye'de batılılaşma hususunda gerçek inkılab Türk müziğinde yapıldı. Avrupa tarzında müziğin Türk halkına dinletilmesi fikri Mustafa Kemal Atatürk'den çıktı. Önderin fikirleri zamanın çok ilerisinde gidiyordu. Musiki de çağdaşlaşma niyetini ilk defa 1928 yılı yazının akşamında Saraybumu'nda kendini selamlayan büyük bir kalabalığa açıkladı. Kelimeleri o zaman büyük bir sansasyona sebeb oldu. Bazı gelişmelere ve zorla Avrupa müziğinin ülkeye sokulmasına rağmen Türk müziğinin yapısı 19. yüzyıldakinin aynı idi. Türk müziği küçük bandolarla, başka bir deyişle "ince saz" ile icra ediliyordu. Buna melankoli tavnnda solistler refakat ediyordu. Burada kemanın yanısıra, tamamen doğuya mahsus ud, kanun ve ney de kullanılıyordu. Mamafih büyük kasabalarda askeri

16. August Ritter, a.g.e., s. 171.

17. Galip Karakaya yaş 70. 1952 yılında eski bir dost olarak Cevat Şakir Kabaağaçh ile onu Istanbul Kumkapi'da bir meyhanede ziyaret ettikleri zaman Neyzen Tevfik bu deyimi Türk musikisinin 1952 yılı hakkında konuşmuştur. Galip Karakaya ile 1993'de Bodrum'da yapılan görüşme. 
ve sivil bandolar hafif sesli Avrupa müziğini ve milli müziği de çalıyordu.

Bir zamanlar Osmanlı sarayında Oda Orkestrası Kondoktörlüğü yapmış olan ve Ankara'da konserler veren müzik şefi Osman Zeki Üngör, bu bandolarla klasik müzik parçalan icra etmeyi denemişti. Zeki Bey son yıllarda Riyaset-i Cumhur orkestrasını yönetti. Sezon boyunca haftalık senfoni konserleri verirdi. Bu zat Türkiye'deki müzik standardını hem icra yönünden hem de kapasite açısından oldukça ilerletti.

Konser müzisyenlerinin eğitimi ilk önce İstanbul'daki Müzik Akademisinde yapılıyordu. Sonra burası daha genişletilerek Müzik Konservatuan ve Dramatik Sanatlara dönüştürüldü.

Bu iki enstitü çalışmalarla öğünülecek bir neticeye ulaștı. İlerleme yaptı, belli bir ölçüde daha iyi için önder oldu. Fakat daha hızlı modem gelişmeler için genel arzuyu başaramadı. Nedeni ise, gerçek bir başannın vazgeçilmez unsurlarından olan para desteği ve buraya uygun ögretmenin verilmemesi idi.

1928'de Atatürk'ün haykırışı halkı canlandırdı ve onlanın coşkusunu dürttü. Bazı hükümet dairelerine ve ülkenin ruhi merkezlerinin müzik problemlerini daha akıllıca ele alıp işleme işaretini başka bir deyimle müzikte reform şuurunu Mustafa Kemal Paşa verdi. Ülkemizde bir miktar kabiliyetli Türk genci devlet bursu ile dış ülkelerde müzik tahsili yapmaya ve çeşitli müzik aletlerini kullanmak için gönderildi. Gönderilme hızı arttı. Ayrıca İstanbul Konservatuannın düzenlenmesi ciddi ve enerjik bir şekilde ele alındı.

Böylece Cumhuriyetin yeni müzik anlayışı Türk müziğinden ahınan motifleri içeren batı tekniği ile takviye edilen dinamik ve neşe ifade eden yeni bir tür müzik idi.

Yunus Nadi'de bu hususta: "Gaye asri ve milli müziği yaratmak yahut daha doğrusu milli müziği asrileştirmek, onu bütün dünyaya hitab edebilecek bir seviyeye çıkarmaktır.

Bethoven'in senfonisi yanında Türk sanatkarlarının eserleri ve halk şarkıları da dinletilmeli, her şeyden evvel milli zevki korumak şartur. Esasen mevcut olan milli his garb tekniği ile kuvvetlendiği zamandır ki, Türk musıki herkese hitab edebilen bir sanat olacaktır. Ruslar böyle yapmışlardır. Yerli sanatlarını atmadılar. Türk esasen sanatkar bir ruha maliktir. Bu bir iddia değil hảkikattir.

Türk'ün kendi yarattığı bir müziği vardır. Halk musikimizde deha vardır. Bu dehayı benimseyip bütün dünyaya duyuracak olan bir dehaya muhtacız. Onu yetiştireceğiz" diyordu ${ }^{18}$.

18. Yunus Nadi, Cumhuriyet Gazetesi, 12.11.1932, sayı 3060. 
Aynı gazetede Nadir Nadi: “Alaturkayı Garb tekniği ile karışurmak, ıhlamur ağacına gül fidanı aşılamak gibi bir hareket olur" derken ${ }^{19}$, Ruşen Ferit Bey de; "Musıkimize Avrupa elbisesi giydirmek Zaro Ağa'ya frak ve slindir şapka, Avrupalıya fes giydirmeye benzer, ${ }^{20}$ diyerek yapılmak istenen yeniliği küçümsemeye çalışıyordu.

Bütün bu lehte ve aleyhte eleştirilere rağmen şu andaki toplumumuzda batı ve doğu tipi paralel olarak başbaşa gitmektedir. Toplumumuzun bir kesimi batı müziğini sevmiyor, çünkü anlamıyor. Bir şeyi sevmek için onu anlamak ve kurallannı bilmek gerekir. Zaman içerisinde batı türü müziğin toplumumuzda daha fazla işlerlik kazanma ihtimali hayli fazladır. Bu iki tür müzik anlayışından birisi diğerine galebe çalacaktır.

Kurtuluş Savaşını başan ile sonuçlandıran Mustafa Kemal Paşa Türkiye'ye çağdaşlaştırmak için birçok alanda inkılablar yapmıştır. Bunlardan birisi de yukanda görüldüğü gibi müzik alanında yapılan yenileşmedir.

19. Nadir Nadi, Cumhuriyet Gazetesi, 17.12.1932.

20. Ruşen Ferit, Cumhuriyet Gazetesi, 16.12.1932. 